\title{
Por uma germanística "menor": \\ W. G. Sebald e a "pequena" literatura da periferia austríaca, e de outros lugares
}

\author{
Uwe Schütte \\ Aston University, U. K. \\ u.schutte@aston.ac.uk
}

\section{Tradução}

Cristiane G. Bachmann e Ruth Bohunovsky

\section{Revisão}

Maria Aparecida Barbosa.

Certamente não é por acaso que faltam os nomes dos clássicos da formação burguesa na bibliografia crítica de W. G. Sebald. Na função de professor de literatura alemã, evidentemente ele se ocupou dos principais representantes do cânone, tais como Lessing, Goethe e Thomas Mann, e lecionou sobre as respectivas obras. Em suas publicações na área dos estudos literários, porém, Sebald os evitou. Sua paixão se dirigiu quase exclusivamente a obras literárias surgidas na margem do território de língua alemã e na periferia do cânone estabelecido.

Sobressai, logo à primeira vista, a atenção muito maior que Sebald dedicou a autores austríacos e/ou alemânicos, em comparação à que destinou a escritores alemães. Uma análise mais detida sobre os nomes dos escritores austríacos abordados por ele revela alguns que pelo menos por certo período - conseguiram fazer parte do cânone: ao lado de clássicos como Adalbert Stifter, Franz Kafka, Hugo von Hofmannsthal ou Joseph Roth, constam nomes de autores contemporâneos bem-sucedidos como Elias Canetti, Thomas Bernhard, Peter Handke 
e Gerhard Roth. Contudo, não nos enganemos. São igualmente marcantes as ausências: nada de Franz Grillparzer (mas sim Charles Sealsfield/Carl Anton Postl), nada de Robert Musil (mas sim Peter Altenberg), nada de Heimito von Doderer (mas sim Jean Améry). O enorme interesse de Sebald pela literatura para além do mainstream é incontestável.

Mas é igualmente marcante a coincidência biográfica: também Sebald foi durante muito tempo alguém que transitava pelas margens, isto é, um estudioso da literatura que vinha de uma província no sudoeste da Alemanha e cujos idiossincráticos trabalhos de qualificação acadêmica - a dissertação sobre Carl Sternheim e a tese sobre Alfred Döblin — o destinaram a assumir uma posição de clara distância em relação à área consagrada da germanística. Em vista de motivos pessoais, que expôs em parte nos seus escritos literários, em parte em entrevistas e ensaios, ele é levado a tornar-se um representante da germanística internacional que passou a maior parte da sua carreira numa universidade situada numa província (porém nada provinciana) na região leste da Inglaterra. ${ }^{1}$

Todavia, Sebald entendeu seu exílio voluntário na periferia do mercado literário e da germanística nacional como uma vantagem. Numa série de artigos e comentários em parte críticos, em parte polêmicos, deu continuidade à tendência que se iniciou na sua dissertação e na sua tese de distinguir-se dos esforços (aos seus olhos) exagerados da germanística no que tange ao processo de canonização literária. Nesses textos, o interesse primordial de Sebald não era tanto partir para ataques ad personam - embora pareça assim à primeira vista, como no caso de Alfred Andersch —, mas, sim, ressaltar questões que considerava fulcrais, por exemplo, a forma de lidar com o Holocausto, a função da literatura ou a relação entre o autor e a obra. Ulrich Simon ressaltou que tal provocação bem calculada era um procedimento argumentativo constante de Sebald, desde a dissertação até o ensaio sobre Andersch e seu livro sobre a guerra aérea: “As argumentações e sua representação estão à procura do confronto" (SIMON, 2005, p. 80).

\footnotetext{
${ }^{1}$ Sem querer dar um peso muito grande aos contextos biográficos, mais dois aspectos me parecem relevantes: Sebald assumiu uma posição limítrofe na vida institucional da University of East Anglia e não morou diretamente na cidade, mas num povoado mais distante de Norwich. Certa vez, contou-me, ainda, que a mera ideia de ir até a metrópole londrina e, sobretudo, a ideia de ter um emprego lá o apavorava.
} 
Foi provocativa também sua dedicação a não poucos autores que, no fundo, não se encontravam ao lado do cânone, mas, antes, abaixo dele ou fora do âmbito do que se costuma chamar "literatura". São paradigmáticos nesse contexto o escritor esquizofrênico Ernst Herbeck e o cineasta, ator, artista, dramaturgo e escritor anarquista Herbert Achternbusch. Ambos os autores representam exemplos extremos, porém Sebald entendia seus textos como paradigmas de uma forma de literatura "menor" e por isso para ele ainda mais importante. Sobre os poemas esquizofrênicos de Herbeck, escreveu que esse tipo de literatura determina

o lugar das nossas esperanças de maneira mais exata do que o discurso ordenado. [...] Na medida em que a cultura assim como a ciência sobre ela são captadas pelo espírito administrativo, cresce a importância potencial da literatura menor, e Herbeck deve ser entendido como o seu expoente. ${ }^{2}$ (SEBALD, 1985, p. 161).

Num comentário sobre os textos de Achternbusch, que - usando um conceito da poética de Ernst Jandl - poderiam ser caracterizados como notas escritas em uma linguagem "degenerada", Sebald aponta, evidentemente com o intuito de elogiar: "Poucos conseguiram aproximar-se tanto da linguagem da esquizofrenia sem perder a razão". Por isso, as linhas de Achternbusch são lidas por Sebald como se fossem "o tributo de alguém que conseguiu se salvar aos seus irmãos que, lamentavelmente, vivem no isolamento" (SEBALD, 1983, p. 77). Ao fazer uma confrontação com a literatura estabelecida, Sebald coerentemente toma partido:

Se compararmos os textos de Achternbusch com as sequências artisticamente torneadas dos grandes senhores escritores, imediatamente se torna claro que esses textos compreendem com uma estupenda exatidão a nossa realidade, que deixou de ser confortável há muito tempo (SEBALD, 1983, p. 78).

Enquanto se costuma louvar os grandes realistas do século XIX ou escritores como Mann e Doderer como produtores daqueles textos que nos ajudam a entender o essencial do seu tempo, Sebald se mantém fiel a escritores "pequenos" e marginalizados, como Herbeck e Achternbusch, cujos textos selvagens e indômitos não apenas nos possibilitam uma compreensão mais adequada da nossa realidade, mas também nos fornecem linhas de fuga de uma realidade um tanto quanto lastimável. Ao recusar o conceito (pre)dominante de literatura

\footnotetext{
${ }^{2}$ N. T.: Todas as traduções são nossas, salvo menção em contrário.
} 
(confira Achternbusch) ou ao ser dela excluída (confira Herbeck), essa literatura "menor" se torna um privilegiado refúgio de esperanças soterradas, um suporte de um outro selvagem.

É mais que evidente que fazemos aqui o empréstimo terminológico do conceito de littérature mineure [literatura menor], desenvolvido por Gilles Deleuze e Félix Guattarri, a partir do exemplo da obra de Kafka - um autor que, não por acaso, ocupa um papel central no corpus dos escritores apreciados por Sebald, como se mostra no conjunto de diversos $\operatorname{artigos}^{3}$. Mas é bem evidente também que o objetivo de Sebald não foi o de comprimir os dois escritores no espartilho de uma teoria literária pós-estruturalista. Se precisássemos denominar algo que poderia ser o fundamento teórico da análise literária de Sebald, seria muito mais útil nos remetermos a um antropólogo associado com o estruturalismo, a saber: Claude LéviStrauss e seu conceito de pensée sauvage [pensamento selvagem].

As diretrizes e os estímulos interpretativos inspirados por tal contexto teórico e que estão presentes nos quatro ensaios sobre Herbeck e Achternbusch podem ser encontrados também em explanações sobre outros escritores, especialmente aqueles associados com o rótulo (in)adequado da "Literatura de Graz". Em consonância com a metodologia literária conscientemente diletante de Achternbusch e Herbeck, e sem nenhuma pretensão sistemática e muito menos definitiva, pretende-se, no presente artigo, fazer algumas observações sobre a análise de textos marginais. Desse modo, seguindo-se as leituras de Sebald, intenta-se traçar ligações entre autores cujos textos não costumam ser considerados afins.

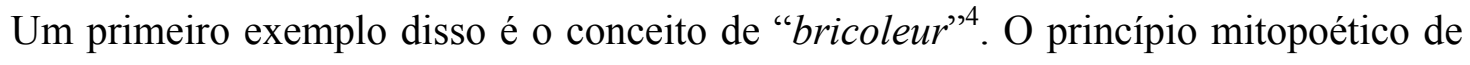
construção da "bricolagem”, na definição de Lévi-Strauss, é usado por Sebald para, a partir do exemplo de Achternbusch, estabelecer uma diferença entre o engenheiro e o bricoleur no âmbito da literatura. Segundo essa diferenciação, um escritor bem-sucedido representa

\footnotetext{
${ }^{3}$ Ver, por exemplo, nas seguintes publicações de Sebald: "Das unentdeckte Land. Zur Motivstruktur in Kafkas Schlo $\beta^{\text {“, „Das Gesetz der Schande. Macht, Messianismus und Exil in Kafkas Schlo } \beta “, ~ „ V i a ~ S c h w e i z ~ i n s ~ B o r d e l l . ~}$ Zu den Reisetagebüchern Kafkas“ e „Kafka im Kino. Über ein Buch von Hanns Zischler.“

${ }^{4}$ Numa entrevista dada a [crítica literária austríaca] Sigrid Löffler, Sebald deixou claro que o bricolage constitui também a base do próprio trabalho literário: "Eu trabalho segundo o sistema de bricolage - no sentido de LéviStrauss. Trata-se de uma forma de trabalho selvagem, de um pensamento pré-racional, em que se remexe em peças encontradas e acumuladas de modo aleatório até que elas combinem de algum jeito". (LÖFFLER, 1997, p. 136). Sobre o conceito de bricolage em Sebald, veja também Niehaus, Öhlschläger (2006).
} 
o tipo do engenheiro [...] que, "no que tange às pressões expressas num objeto civilizatório, sempre tentará abrir uma passagem para se colocar acima dele, enquanto um bricoleur (Achternbusch) se posiciona abaixo dele, seja por vontade própria, seja por imposição". (SEBALD, 1983, p. 77)

Portanto, Achternbusch é capaz de produzir “expressões de linguagem e imagens que nunca ocorreriam a um literato profissional, nem durante seus sonhos".

O princípio mitopoético de bricolage, que se refere à reunião improvisada de materiais, fragmentos e elementos heterogêneos — ou seja, odds and ends — que foram acumulados de modo aleatório e que chegam a formar um mito novo e surpreendente, ocupa também um papel decisivo na percepção do desalinhamento da linguagem de Herbeck, que resulta da desorganização psicótica, em vez de difamá-la como um mero sintoma de uma doença:

Os deslocamentos nas estruturas de palavras e frases oriundos da manipulação do bricoleur são um meio de descrição poética do mundo cuja arte se constitui menos no deciframento do que na codificação da realidade, inclusive da realidade linguística. (SEBALD, 1985, p. 139).

Em um dos seus melhores artigos de teor crítico-literário - o ensaio sobre o romance Landläufiger Tod [Morte alastrada], de Gerhard Roth —, Sebald consegue, a partir de tais premissas, definir o procedimento quase arcaico de coletar e bricoler como a contribuição mais significativa de Roth. Trata-se de uma atividade

que utiliza todos os objetos encontrados, todos os fragmentos da natureza e todos os pedaços da história despedaçada que chegam às mãos do autor como material de construção no processo de reconstrução de uma vida que está cada vez mais se esvaindo. (SEBALD, 1991, p. 149).

O olhar de Sebald, treinado pelos poemas de Herbeck para reconhecer formas literárias de uma mitopoesia primitiva, possibilitou-o decifrar tanto a estética original quanto a força sugestiva da grande quantidade de frases axiomáticas sem sentido, como "Am Tag des Hirschen wird das Gewitter mit einer bestickten Fahne geehrt" ["No dia do cervo, a tempestade será homenageada com uma bandeira bordada"] (ROTH, 1984, p. 141), sobre as quais outros intérpretes tinham muito pouco a dizer. Sebald entendeu esse procedimento como algo guiado pelo pensamento analógico do bricolateur, que, 
em oposição ao sistema da escrita e da organização sintática de elementos potencialmente significativos, procura introduzir a descentralização da linguagem por meio de dissociações e deslocamentos. (SEBALD, 1991, p. 148).

Mediante uma análise empática e sensível das frases supostamente sem sentido de Roth, Sebald consegue, assim, libertar a carga poética dessas passagens do Landläufiger Tod [Morte alastrada], geralmente ignoradas devido à sua dimensão hermética. Prova-se, desse modo, que a contribuição literária desse romance fundamenta-se no fato de que Roth, na forma do narrador esquizofrênico Franz Lindner, não empreende nenhuma simulação de textos psicopatológicos (como o fez, por exemplo, Heinar Kipphardt nas diversas versões do romance $M \ddot{a} r z)$, mas que adapta e emula os princípios de construção textual que ocorrem na esquizofrenia.

Os textos crítico-literários de Sebald devem ser lidos como material de apoio que possibilita a outros leitores encontrar o sentido oculto naquilo que aparentemente não faz sentido. Está embutida nisso uma tomada de partido pelos autores marginalizados e uma empatia inter-humana, incompatível com as pretensões da "objetividade científica". 5 Ao mesmo tempo, Sebald destaca a livre expressão da empatia entre criaturas como uma das características mais marcantes dos textos de Herbeck e Archternbusch. No seu tocante necrológio dedicado a Herbeck, remete ao parentesco totêmico que o poeta esquizofrênico deformado pelo lábio leporino sentia com a figura da lebre e o qual expressou numa série de poemas e outros textos (ver Sebald, 2003, p. 171-178).

Com relação a uma cena hiperbólica em que Achternbusch descreve como os pacientes moribundos do asilo público de idosos, numa praça de Munique, são empurrados da janela do sótão em direção ao telhado, onde são deixados indefesos para serem devorados pelas gaivotas, Sebald comenta que tais imagens podem certamente "nos ensinar a ter medo" e prossegue:

Obviamente, as vítimas de tal sistema sinistro de descarte já não tiram nenhum proveito da revelação que nós temos ao ler tais passagens. Por outro lado, o potencial emocional necessário para uma mudança das condições sociais por nós

\footnotetext{
${ }^{5} \mathrm{O}$ ensaio sobre Herbeck deve ser lido, portanto, junto com a passagem de Vertigem (SEBALD, 2008, p. 35-39) em que Sebald relata uma visita e um passeio que fez com o paciente de uma clínica psiquiátrica.
} 
organizadas e toleradas só pode ser alcançado por meio da evocação do sofrimento dos nossos camaradas presos. (SEBALD, 1983, p. 78).

Portanto, a literatura marginal não é apenas um reduto artístico de empatia e solidariedade, mas também um lugar de uma estética de resistência, conservando uma aspiração utópica de mudança social.

É óbvio que Sebald sabia muito bem que a reformulação nos pilares da nossa organização social só seria cabível após a emancipação individual. Desse modo, explica-se por que estão entre os interesses centrais dos seus trabalhos crítico-literários os limites e as possibilidades de emancipação por meio da escrita literária. Em relação a isso, a literatura austríaca (pós-guerra) fornece-lhe material ilustrativo em abundância. Sebald registra de modo elucidativo:

De fato, toda obra monomaníaca de Josef Winkler, e a maior parte da literatura contemporânea inspirada por Graz, é uma tentativa de compensar a experiência da humilhação e dos estupros morais por um olhar maléfico, direcionado à própria origem [...]. (SEBALD, 1990a, p. 147).

Algo semelhante pode ser dito sobre autores como Franz Innerhofer, o jovem Peter Handke e outros:

Sujeição, opressão, escravidão, aprisionamento, exploração — quase todos os jovens escritores austríacos se viam obrigados a ambientar nessa lista as experiências sociais que tiveram na sua pátria [...]. (SEBALD, 1990a, p. 148).

Escrever como forma de libertar-se da desqualificação social, a literatura como emancipação — tudo isso constitui, para Sebald, um processo de capacitação que

em muitos aspectos ocorreu de modo semelhante à tendência de assimilação dos judeus no final do século XIX e início do século XX e que, portanto, produziu também uma literatura de grande impacto e de alta qualidade [...]. (SEBALD, 1990a, p. 149).

Com base em uma seleção de histórias do gueto escritas por autores judaicos do século XIX, Sebald chamou a atenção para as aporias de tal empreendimento (ver SEBALD, 1991, p. 40$64)$. 
Para poder usar a literatura como uma saída de condições sociais desfavoráveis, é necessário dar o primeiro passo radical, e fundamental, de sair da menoridade não autoinfligida por meio da conquista de uma linguagem própria. Sebald remete à obra do jovem Peter Handke, que ele entende como paradigmática nesse sentido e na qual

é de importância central a relação entre a falta, o encontro e a perda da linguagem. Em toda parte há mudos, seres sem palavras, pelos quais o narrador relata sobre a danificação e a destruição de sua pessoa [...]. (SEBALD, 1990a, p. 148).

Naturalmente o radar da germanística não deixou escapar tudo isso e produziu uma série de estudos sobre a literatura "de Graz". Porém, o processo mediante o qual a fala e a escrita literária tornam-se instrumentos de libertação de condições precárias desfavoráveis é visto por Sebald de forma muito mais extrema no caso de escritores verdadeiramente "menores" como Herbeck e Achternbusch: com toda clareza possível, ele constata que,

quando o jovem monge diz que sente dor na língua e que ele não encontra nenhum sentido na língua alemã, ele tira as palavras da boca de Achternbusch. Quem, assim como esse escritor, conseguiu desvencilhar-se da afasia talvez saiba o que significa quando alguém não consegue mais abrir o bico [...]. (SEBALD, 1983, p. 77).

Para essa temática, é de suma importância o texto dramático Ella, de Achternbusch. Trata-se da biografia da existência marginal paradigmática de Ella — personagem que dá nome à peça - que, durante toda a sua vida, levou uma existência sem direito a tomar decisões por conta própria e,

após ser empurrada de um homem para outro, de um lugar a outro, do abrigo emergencial ao asilo dos sem-teto, passado por filhos natimortos e tentativas de suicídio, chega ao hospício de Haar, onde, ao longo de 12 anos, é tratada de tal modo que só lhe cabe um lugar como força de trabalho num sanatório para doentes pulmonares. (SEBALD, 1990, p. 301).

A peça mostra Ella totalmente arruinada num galinheiro sujo, sentada imóvel e calada muda diante de uma televisão ligada. Ou seja, ela já não fala mais. Mesmo assim, conhecemos toda a história do seu sofrimento por intermédio do seu filho Josef, que, usando um avental e um enfeite na cabeça feito de penas de galinha, se coloca no lugar da sua mãe para poder contar 
sem piedade ao espectador todo o horror da biografia arruinada da mãe, que culmina na seguinte frase:

Então, toda a minha vida foi um bater e empurrar e espancar e escarnecer e um debochar e um monte de coisas assim. Uma boa hora, em toda minha vida, eu nunca vivi. (ACHTERNBUSCH, 1986, p. 343).

Devemos inferir que tal constatação vale também para Josef, sobre cuja vida como filho de Ella nada é dito, mas sobre a qual o espectador pode levantar as próprias hipóteses.

Conforme já apontado, o advento de uma literatura geralmente reunida sob o rótulo de "antipatriótica" [Antiheimatliteratur] e que ocorreu na Áustria pós-guerra foi atribuído por Sebald à necessidade dos autores de lançar "um olhar malévolo à própria origem", de modo semelhante como o fez Josef (SEBALD, 1990a, p. 147). Levando em consideração sua propensão para interpretações inspiradas na antropologia, não é de se admirar que Sebald tenha recorrido frequentemente ao nome de Elias Canetti para corroborar sua argumentação - o grande ensaio Massa e poder foi usado por ele na maneira mais adequada possível, ou seja, como um repertório desordenado de mitos, histórias e observações. Em consonância com tal abordagem, no ensaio sobre Ella, Sebald remete à prática dos selvagens, relatada na peça, de lembrar-se intensamente de ferimentos e dores dos antepassados e, assim, estabelecer uma relação com eles (CANETTI, 1960, p. 385s.).

Em Ella, Achternbusch opera exatamente dentro dessa matriz de olhar malévolo para a própria origem e de identificação empática com os antepassados. Sobre isso, Sebald comenta:

\footnotetext{
Invoca e realiza-se a volta dos antepassados por meio da assimilação dos seus sofrimentos por um descendente. Esse modo de re-memoração concreta exige, portanto, uma transformação — isto é, uma arte em grande medida soterrada em nossa civilização e para a qual restaram apenas alguns domínios, sob constante ameaça de extinção, no trabalho artístico, um dos últimos reservatórios do pensamento selvagem. (SEBALD, 1990, p. 302. Grifo nosso).
}

Sebald afirma que não é apenas no "monólogo autista [de Josef] que a arte da transformação funciona", mas que,

nos textos de Achternbusch, se encontram reiterados alguns indícios de uma transformação estática, na forma como é descrita por Canetti. E é justamente essa dimensão do seu trabalho que tende, a partir dela mesma, a aproximar-se do teatral. 
Detenhamo-nos um pouco em Canetti. Ganhador de um Prêmio Nobel, certamente ele não pertence ao círculo de autores menores; porém, sua obra mostra em muitos aspectos uma estreita relação com aquilo que está em questão aqui. Sebald não o via como um "guardião da transformação" - como Canetti havia sido designado numa coletânea de 1985 —, mas sim como um perito da transformação. Essa avaliação foi feita por Sebald num dos seus primeiros artigos, publicado em 1972 na revista "Literatur \& Kritik" ["Literatura \& Crítica"] — um ensaio dividido em três secções separadas e que, devido à sua forma insólita, marcou a estreia efetiva de Sebald como crítico literário, já remetendo para ensaios posteriores, que aboliram os limites entre literatura e crítica literária. No mesmo texto, é citada também a fala de Canetti em homenagem ao $50^{\circ}$ aniversário de Hermann Broch, em que comparou a essência do verdadeiro poeta com a de um cão. Estabelecendo uma relação com Forschungen eines Hundes [Investigações de um cão], de Kafka, livro em que "o cão se torna um veículo de salvação do homem, desde que este reconheça o modelo que o animal lhe apresenta", Sebald resume:

Imitar o cão parece ser, desde então, a tarefa dos verdadeiramente escolhidos, e acatá-la não deve, como Fischerle tenta comprovar a Kien, ser avaliado como algo inferior do que o desejo pela Imitatio Christi [...].(SEBALD, 1972, p. 283).

Tais processos de transformação entre homem e animal continuaram ocupando Sebald, que, no seu ensaio sobre Herbeck, remete frequentemente à identificação quase simbiótica do poeta esquizofrênico com aquilo que este denominou "Thierenschaft" — um neologismo para “mundo animal” (HERBECK, 1992, p. 91) —, refletida num verdadeiro bestiário poético. Um exemplo:

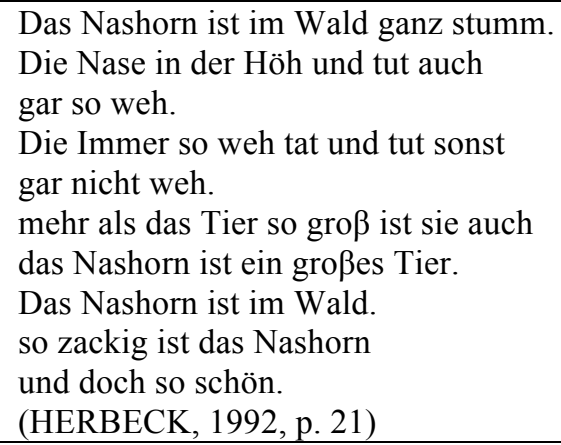

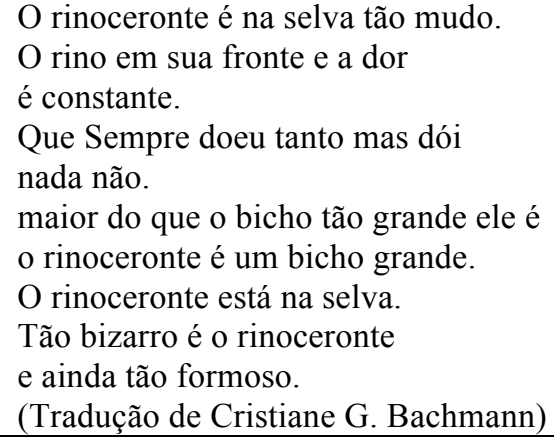


Na obra do irmão espiritual de Herbeck da Baixa Baviera, podemos observar uma proximidade semelhante em relação aos animais: "Não é por acaso que nos textos de Achternbusch há todo tipo de animal evidenciando seu modo errático de vida”, Sebald nos faz lembrar e continua:

leão, hipopótamo, camelo, elefante e lebre possuem para ele, obviamente, uma função emblemática. Isso não deve causar nenhuma surpresa, pois como já sabe o índio, seu destino está estreitamente entrelaçado com o do animal totêmico [...]. (SEBALD, 1983, p. 78).

A identificação solidária com o animal — remetendo-nos a Deleuze e Guattari, poderíamos falar em uma "encarnação animal” [no sentido de "transformação em animal"] — marca mais uma linha de fuga que Sebald nos faz notar na obra de Herbeck, como o reverso de uma outra projeção — da "transformação em anão". "A mitologia do conto de fada conhece muitos exemplos da correspondência entre a experiência do sofrimento e o sonho de uma transformação num ser menor" (SEBALD, 1985, p. 147), comenta Sebald acerca de uma das máximas de Herbeck, qual seja:

\begin{tabular}{|l|l|}
\hline Je größer das Leid & Quanto maior a dor \\
desto kleiner der Dichter & tanto menor o poeta \\
Umso härter die Arbeit & Tão mais árduo o labor \\
Umso tiefer der Sinn & Tão mais profundo o sentido \\
& \\
(HERBECK, 1992, p. 68) & (Tradução de Cristiane G. Bachmann) \\
\hline
\end{tabular}

Quase surge aí a impressão de que essas palavras, proferidas com autoridade assombrosamente perturbadora, revelem um tanto de autoconhecimento, da consciência de ser um poeta "menor". Isso é corroborado ainda pelo fato de Herbeck, no poema "Durma, meu cérebro, durma" ["Schlaf, mein Gehirn, schlaf"] conceber um contraprograma minoritário para o conceito de alta cultura, baseado no fundamento da racionalidade: 


\begin{tabular}{l|l}
\hline Kleines Denken, und singen trägt & Pequeno pensar, e cantar é um passo \\
dazu bei. Sowie die kleinen Volks- & pra isso. Qual pequenas canções \\
lieder, lassen die Arbeit des Gehirnes & populares, fazem o trabalho cerebral \\
nicht aufkommen und das Gehirn & $\begin{array}{l}\text { desaparecer e o cérebro } \\
\text { adormece. }\end{array}$ \\
schläft. & (Tradução de Cristiane G. Bachmann) \\
(HERBECK, 1992, p. 153) &
\end{tabular}

Tal "transformação em anão" representa um movimento retrógrado que se opõe ao desvario progressista e expansionista da ideologia atualmente imperante e cuja manifestação literária Sebald procurou também em outros autores, como no exemplo notório dos microgramas de Robert Walser, o poeta do diminutivo. O mesmo gesto de diminuição encontra-se também em Canetti, cuja verdadeira obra-prima se constitui na pequena forma das notas e dos aforismos. No seu ensaio "System und Systemkritik bei Elias Canetti" ["Sistema e crítica do sistema em Elias Canetti"], Sebald cita a seguinte nota de Canetti:

\begin{abstract}
Seria belo, a partir de certa idade, tornar-se menor a cada ano e voltar pelos mesmos degraus que um dia se subiu com tanto orgulho. [...] Os reis mais velhos seriam os menores; os bispos tornar-se-iam cardeais, e os cardeais olhariam de cima para baixo para o Papa. Nenhuma criança poderia desejar tornar-se algo grande. (CANETTI, 1960, p. 9).
\end{abstract}

Sebald tinha uma evidente fascinação por processos de transformação, fosse em termos do fenômeno social de emancipação de condições inferiores por meio da literatura, fosse no sentido da supressão de condições miseráveis encenada literariamente, como se vê na obra de autores "menores". O que me parece essencial nisso é o ato de transpor fronteiras, presente nesses dois movimentos. Para finalizar, isso será ilustrado aqui com base em dois artigos sobre textos de Peter Handke. Num primeiro momento, dirigimos o olhar para a transposição da fronteira precária "entre o comportamento normal e o patológico" naquele obscuro acontecimento que geralmente denominamos como eclosão da loucura (SEBALD, 1985, p. 115). Sebald interessava-se pela zona limítrofe entre literatura e psicopatologia não apenas nos exemplos evidentes de Herbeck e Achternbusch, mas também em Die Beschreibung des Unglücks [A descrição da infelicidade], ao estudar aspectos da transposição de fronteiras da normalidade para a patologia na vida e/ou na literatura por meio de autores austríacos como Stifter, Schnitzler, Hofmannsthal, Bernhard ou Gerhard Roth. 
No início do seu ensaio sobre $O$ medo do goleiro diante do pênalti, Sebald lamenta o déficit de descrições de casos psiquiátricos no que diz respeito à eclosão da esquizofrenia, já que essas descrições se baseiam "na maioria das vezes, nas informações dos membros familiares e outros agentes das instâncias da ordem social" (SEBALD, 1985, p. 115). A psiquiatria, critica Sebald, tem mais interesse na categorização dos sintomas de uma mudança de personalidade do que na anamnese da infelicidade. O conto de Handke que trata "dos estados de medo do antigo goleiro Bloch” indaga, portanto,

se as falhas da ciência não poderiam ser compensadas por uma disciplina que, por natureza, depende de um grau de empatia que permite não apenas diagnosticar, mas também compartilhar e entender a transposição de limites (SEBALD, 1985, p. 115116).

Obviamente, Sebald se refere aqui à disciplina empática da literatura, sem deixar de criticar ao mesmo tempo “que o 'enigma' da esquizofrenia ainda não foi resolvido porque poucos tentaram descrever o que acontece ao transpor-se essa fronteira" (SEBALD, 1985, p. 118).

Remetendo-se aos textos autobiográficos de Herbeck, repletos de lacunas e ausências, Sebald formula a hipótese "de que a gênese da esquizofrenia não deveria ser fixada naquilo que aconteceu, mas nos espaços em branco da vida anterior" (SEBALD, 1985, p. 117). O que chama a atenção de Sebald no conto de Handke é que ele, por um lado, produz perturbadores espaços em branco na vida anterior do antigo goleiro - o que impossibilita uma explicação racionalizante para a desorganização que remeta a fatores biográficos como crises familiares, abusos ou traumas. Por outro lado, o texto desenvolve, de acordo com Sebald, uma sintomatologia do estranhamento e do medo do pânico que deixa vislumbrar quais condições imediatamente precedem a transposição para o patológico. Assim, com o conto, Handke forneceu uma obra "que está comprometida tanto com os princípios da ciência quanto com os da arte" (SEBALD, 1985, p. 116).

Devemos entender a imagem ideal proposta por Sebald de uma literatura que satisfaz tais exigências científicas como o reverso de uma crítica literária que, em termos de estilo, forma e metodologia, se sente mais comprometida com a literatura do que com os estudos literários, ou seja, praticamente uma mútua transposição de limites sob os auspícios da empatia. Nesse ponto, é mais provável que se trate de uma dialética que procura fundir essas 
duas modalidades de fala num nível discursivo mais alto - e não de uma desconstrução do limite entre a literatura e a fortuna crítica, cujo objetivo é antes um nivelamento da relação hierárquica desses dois tipos de fala.

Uma segunda forma de transgressão proporcionada pela literatura que teve grande importância para Sebald foi a perfuração da visão iluminista do mundo, marcada por um implacável desencantamento e pela imanência. Em certa medida, tratava-se novamente de algo "sublime": Sebald interessava-se pelo transcendental e por trazer à tona o acesso soterrado que leva ao espaço desacreditado de um pensamento e de um sentir além da razão instrumental. Já na primeira frase do seu primeiro ensaio crítico sobre literatura, o referido “Gedanken zu Elias Canetti” ["Reflexões sobre Elias Canetti”], Sebald reclama que hoje em dia "a metafísica entrou num estado de rigidez cadavérica" (SEBALD, 1972, p. 280).

$\mathrm{Na}$ passagem introdutória do ensaio sobre Die Wiederholung [A repetição], de Handke, Sebald funde um apelo pela inalterada relevância da metafísica com uma repreensão dos estudos literários: a metafísica que Handke desenvolveu a partir de Langsame Heimkehr [Lento retorno] pretende

aplicar na escrita aquilo que aconteceu e que foi percebido. Parece que hoje já não existe mais nenhum procedimento discursivo em que a metafísica ainda possa exigir seu lugar. E, apesar disso, a arte, independentemente de onde e quando ela acontece, tem a mais estreita relação com a área da metafísica. Para aprofundar-se nessa proximidade, o escritor precisa de uma coragem que não devemos subestimar, enquanto obviamente é muito fácil para a crítica e para a ciência, que veem na metafísica nada mais do que um tipo de depósito, satisfazer-se com o comentário geral de que nas regiões mais altas o ar é rarefeito e o perigo de despencar é grande. (SEBALD, 1991, p. 163-164).

Ao olhar repetidamente para a literatura de autores como Achternbusch e Herbeck através de uma lente antropológica, Sebald tem em mente, num primeiro momento, a reabilitação epistemológica de textos de uma literatura "menor", mas sua argumentação vai mais longe, tornando-se bastante abrangente quando fala de fenômenos análogos em textos de autores consagrados. Podemos ilustrar isso referindo-nos mais uma vez a Ella. No entender de Sebald, nessa peça Achternbusch conseguiu produzir um magnífico momento teatral de transformação: 
E por meio dessa transformação é introduzido um ritual de repetição, no qual [...] uma pessoa viva personifica um antepassado distante para assim garantir a transubstanciação de uma pessoa que deixou de viver. No caso de tais processos recíprocos e complexos, trata-se de uma ação comunitária dos vivos e dos mortos, da abolição dos opostos entre diacronia e sincronia, entre o tempo reversível e irreversível. (SEBALD, 1990b, p. 303).

De tal "re-tomada" de um parente morto trata o romance de Handke, que anuncia esse procedimento já no título Wiederholung (entendido aqui no sentido de "Wieder-Holung" ["retomada"]: no verão do ano 1960 ou 1961, o narrador Filip Kobal faz uma viagem à região eslovena com o objetivo de procurar vestígios de Gregor, seu irmão desaparecido. Em meados dos anos 1930, este frequentava a escola agrícola de Maribor, onde queria estudar fruticultura antes de ser convocado para o exército alemão e morrer durante a guerra. Ou seja, passaramse 25 anos entre esses dois cruzamentos da fronteira entre a Áustria e a Iugoslávia pelos dois irmãos, e é exatamente o mesmo ínterim que separa a narrativa atual do relator Filip dos acontecimentos da sua viagem de então. Com isso, o romance é uma repetição por escrito da viagem de Filip no início dos anos 1960, que, por sua vez, repete a viagem de Gregor. Nos dois casos, trata-se de uma tentativa de reconstrução de algo ou alguém definitivamente perdido. Por isso, o romance de Handke confirma de modo exemplar a constatação com a qual Sebald encerrou sua fala por ocasião da inauguração da Casa de Literatura de Stuttgart, em novembro de 2001: "Há muitas formas de escrever; mas apenas na escrita literária ocorre, além de um registro de fatos e da transposição dos limites da ciência, uma tentativa de restituição" (SEBALD, 2003, p. 248).

A maravilhosa leitura que Sebald faz desse romance magnífico e que traz à tona temas como o messianismo, o desejo de redenção, o exílio, a fraternidade, a predileção, a utopia matriarcal, a liberdade de dominação política e outros assuntos ligados à metafísica não pode e não precisa ser aprofundada aqui em todas as suas facetas. Queremos apenas retraçar o processo de restituição identificado por Sebald em $A$ repetição e que começa na estilização que Handke faz da própria biografia na figura do narrador, pois a família dos Kobals, expulsa da sua pátria eslovena "mostra alguns traços que conhecemos da história da própria família do Handke" (SEBALD, 1991, p. 169). Conforme Sebald, não está em questão uma "autobiografia exemplar" idealizada - considerando-se que a família de Kobal mostra 
também alguns traços negativos —, mas sim transposições ficcionais realizadas conscientemente e com um objetivo bem definido, que "podem ser lidas como os desejos de redenção do autor". Trata-se, em primeiro lugar, de uma

\footnotetext{
eliminação o mais abrangente possível de determinado elemento, de um distanciamento o mais abrangente possível da ascendência alemã paterna que, parece-me, pertence aos maiores obstáculos no processo de desenvolvimento psíquico e moral do escritor Peter Handke. (SEBALD, 1991, p. 169-170).
}

Com isso, o romance corresponderia - ao contrário do modelo apresentado de Ella/Josef - a uma tentativa mágica de exorcizar um dos progenitores, ampliando assim em mais uma faceta os aspectos acima discutidos em relação à literatura como meio para emancipar-se de uma origem humilde.

Uma vez transformado na figura de Filip Kobal, Handke estabelece - agora novamente em consonância com o modelo "Ella" - uma relação com o irmão desaparecido na forma de uma "invocação" literária dos antepassados (SEBALD, 1991, p. 174) que vai se intensificando, transformando-se de mera procura por vestígios em tentativa de "repetição" redentora. Em diversos momentos da sua leitura de $A$ repetição, Sebald ressalta a grande importância do messiânico para a construção do romance. Em relação à constelação fraterna, afirma ainda:

\begin{abstract}
$\mathrm{Na}$ tradição messiânica, não está em primeiro plano que os separados finalmente caiam nos braços um do outro, mas sim que continue o esforço para que o mais jovem assuma a sucessão do mais velho, o aluno se torne o professor e que o desejo devoto de redenção, a esperança de uma viagem para o Nono País em companhia [do irmão], numa caleche decorada com motivos de Páscoa, expressa por Gregor em uma de suas cartas do front seja transcrito "para a realização mundana: a Escritura". (SEBALD, 1991, p. 175).
\end{abstract}

E exatamente esse é o desejo que se concretiza para Filip Kobal, e também para Handke na redação do livro. Seria um pouco exagerado chamá-lo de obra sagrada, embora nele e por meio dele transcendam-se os limites do profano de modo semelhante, "embora não comparável" com o ato mágico de invocação na peça de Achternbusch. Achados literários como $A$ repetição pretendem alcançar uma dimensão superior, querem libertar do peso que 
marca nossa condição cotidiana. $\mathrm{O}$ fato de que o leitor do romance encontra repetidamente passagens que "quase transmitem uma sensação de levitação" é, para Sebald,

\begin{abstract}
uma medida da qualidade extraordinária da narrativa, cujo ideal secreto é, no meu entender, o da leveza. Não no sentido de que o narrador seja despreocupado ou descontraído; apenas, em vez de falar daquilo que pesa sobre ele, aplica seu sentido para produzir algo que possa ajudar a ele e ao leitor, que talvez precise de tanto consolo quanto ele mesmo para resistir às tentações da melancolia. (SEBALD, 1991, p. $176-177)^{6}$
\end{abstract}

Ou seja, o que Sebald tentou transmitir por meio de suas leituras (não apenas) de autores "menores" foi a compreensão da literatura como um aceno solidário, um convite para decifrar o potencial libertador inscrito nos textos, apesar de toda força gravitacional das condições externas.

Nos seus Randbemerkungen zum Thema Literatur und Heimat [Comentários marginais sobre o tema literatura e pátria], Sebald defende a tese de

que a reanimação da literatura austríaca (e também da alemã) que se encontrava numa situação desoladora nos anos 1960 não teria sido possível sem que tivesse surgido um tipo de autor identificável num sentido topográfico, social e psicológico a partir da periferia (SEBALD, 1990, p. 150).

Essa é uma constatação também aplicável ao caso do surgimento do germanista e posteriormente também escritor W. G. Sebald, que deixou a periferia da região de Allgäu para estabelecer-se numa periferia no leste da Inglaterra, onde criou uma obra literária que pertence à produção mais extraordinária escrita em língua alemã no final do século XX. Conforme já apontado pela zelosa filologia sebaldiana, essa obra está marcada pela relação intertextual com grandes cânones da história literária, como Stendhal, Proust ou Nabokov (sobre isso, confira as respectivas contribuições em ATZE; FRANZ, 2005). Mas resta como assunto a ser estudado num momento futuro a série de impulsos importantes que a obra de Sebald deve aos subestimados escritores menores.

Sebald não apenas enriqueceu a literatura, mas nos seus artigos e livros também transmitiu estímulos essenciais para a disciplina que estuda a literatura e que se pretende

\footnotetext{
${ }^{6}$ Ver também as observações de Sebald sobre levitação na obra de Nabokov em: Sebald (2003, p. 191-192).
} 
ciência, mesmo considerando que a germanística - como não poderia deixar de ser - se mostrou em grande parte desfavorável às intervenções provocativas, em conteúdo ou forma, na sua prática, executada às vezes exageradamente sem atrito. Seja em suas leituras, seja em suas pesquisas ou em seus ensaios, Sebald sempre voltou a procurar a companhia de autores "menores" para decifrar as mensagens sutis dos seus textos e para tornar visível aquilo que havia sido deixado de lado, por meio de uma leitura empática que, talvez, poderíamos chamar de um início de uma área de estudos literários "menores".

\section{Referências Bibliográficas}

ACHTERNBUSCH, H. Ella. Die Atlantikschwimmer. Frankfurt am Main: Suhrkamp, 1986, p. 327-356.

ATZE, M.; LOQUAI, F. (Orgs.). W. G. Sebald. Lektüren. Eggingen: Isele, 2005.

CANETTI, E. Aufzeichnungen 1942-1948. Munique: Carl Hanser, 1968.

. Masse und Macht. Hamburgo: Claasen, 1960.

HERBECK, E. Im Herbst da reiht der Feenwind. Gesammelte Texte 1960-91. Org. Leo Navratil. Salzburgo: Residenz Verlag, 1992.

LÖFFLER, S. 'Wildes Denken'. Gespräch mit W. G. Sebald. In: LOQUAI, F. (Org.). W. G. Sebald. Eggingen: Edition Isele, 1997, p. 135-137.

NIEHAUS, M. ÖHLSCHLÄGER, C. (Orgs.). W. G. Sebald. Politische Archäologie und melancholische Bastelei. Berlim: Erich Schmidt Vergal, 2006.

ROTH, G. Landläufiger Tod. Frankfurt am Main: Fischer, 1984.

SEBALD, W. G. Gedanken zu Elias Canetti. Literatur und Kritik 65, Salzburgo, p. 280-285, 1972.

Die weiße Adlerfeder am Kopf. Versuch über den Indianer Herbert Achternbusch. Manuskripte 79, 1983, p. 75-79.

Die Beschreibung des Unglücks. Zur österreichischen Literatur von Stifter bis Handke. Salburgo: Residenz Verlag, 1985. 
Damals vor Graz. Randbemerkungen zum Thema Literatur \& Heimat. In: BARTSCH, K; MELZER, G. Trans-Garde. Die Literatur der "Grazer Gruppe". Graz: Droschl, 1990a. p. 141-152.

Achternbuschs theatralische Sendung. In: JAMES, D.; RANAWAKE, S. (Orgs.) Patterns of Change. German Drama and the European Tradition. Essays in Honour of Ronald Peacock. Bern: Peter Lang, 1990b, p. 297-306.

. Schwindel, Gefühle. Frankfurt am Main: Eichborn Verlag, 1990c.

. Unheimliche Heimat. Essays zur österreichischen Literatur. Salzburgo: Residenz $\overline{\text { Verlag, }} 1991$.

. Campo Santo. Org. Meyer, S. Munique: Carl Hanser, 2003.

Vertigem. Trad. José M. M. de Macedo. São Paulo: Companhia das Letras, 2008.

SIMON, U. Der Provokateur als Literaturhistoriker. Anmerkungen zum Literaturbegriff und Argumentationsverfahren in W. G. Sebalds essayistischen Schriften. In: ATZE, M.; LOQUAI, F. 2005, p. 78-104. 